\title{
Desain dan Implementasi Konverter DC-DC Rasio Tinggi Berbasis Integrated Quadratic Boost Zeta untuk Aplikasi Photovoltaic
}

\author{
A. Hafizh Rifa'i, Dedet Candra Riawan, dan Heri Suryoatmojo \\ Jurusan Teknik Elektro, Fakultas Teknologi Industri, Institut Teknologi Sepuluh Nopember (ITS) \\ J1. Arief Rahman Hakim, Surabaya 60111 \\ E-mail: hafizhrifai23@gmail.com, dedet.riawan@ee.its.ac.id, suryomgt@ee.its.ac.id
}

\begin{abstract}
Abstrak- Photovoltaic pada umumnya digunakan untuk mengubah energy matahari menjadi energy listrik. Jika jumlah modul photovoltaic terbatas maka tegangan keluaran yang dihasilkan akan kecil. Untuk menghubungkan ke inverter pada sistem terhubung ke jala-jala, membutuhkan tegangan yang lebih tinggi dari pada keluaran photovoltaic. Untuk mengatasi hal ini, topologi konverter boost banyak dikembangkan untuk memperoleh untuk mencapai rasio pengubahan tegangan yang tinggi.

Pada tugas akhir ini dibahas mengenai desain dan implementasi konverter DC-DC rasio tinggi berbasis Integrated Quadratic-Boost-Zeta untuk aplikasi photovoltaic.. Kelebihan dari konverter ini adalah memiliki rasio konversi yang tinggi dengan duty cycle kecil dan membutuhkan sedikit komponen. Pada pengujian, konverter ini mampu mengkonversi tegangan masukan 18 VDC menjadi 330 VDC pada duty cycle $65,92 \%$.
\end{abstract}

Kata kunci : Konverter, Quadratic Boost Zeta, induktor kopel, duty cycle, jala-jala

\section{Pendahuluan}

$\mathrm{D}$ ALAM membuat sebuah sistem pembangkit listrik tenaga surya banyak sekali komponen yang dibutuhkan terutama ketika ingin dihubungkan dengan jala-jala (grid connected)[1] . Tegangan DC keluaran dari konverter harus dinaikkan terlebih dahulu untuk meningkatkan efisiensi dan meningkatkan rasio konversi. Cara meningkatkan tegangan DC yang paling umum adalah dengan menggunakan konverter Boost . Konverter Boost adalah alat yang digunakan untuk meningkatkan tegangan DC keluaran dari photovoltaic dengan cara mengatur duty cycle. Semakin tinggi tegangan yang dinaikkan maka semakin besar nilai duty cycle. Namun dalam prakteknya peningkatan duty cycle tidak sesuai dengan kondisi dari peralatan yang ada seperti sistem pensaklaran, penyearah dioda, resistor, induktor dan kapasitor, serta semakin besar nilai duty cycle maka mengakibatkan adanya pengaruh elektromagnet.

Berbagai konverter telah diusulkan untuk mendapatkan efisiensi konversi dan rasio penguatan tegangan yang tinggi serta memperkeceil jumlah komponen. Salah satunya yaitu penguatan tegangan menggunakan topologi quadratic boost dan topologi SEPIC [2]. Namun kelemahan dari teknik tersebut adalah arus yang mengalir pada saklar sangat tinggi sehingga mengakibatkan rugi-rugi konduksi serta masih banyaknya jumlah komponen yang memperberat rangkaian alat.

Di sisi DC-DC, peningkatan tegangan rasio tinggi bisa dicapai dengan menggunakan konverter topologi boost atau buck boost DC-DC. Bagaimanapun, telah terbukti bahwa konverter tersebut tidak begitu cocok karena tingginya resistansi seri ekuivalennya (ESR), yang mempengaruhi duty cycle dan menurunkan efisiensi konverter dan rasio penaikan tegangan[3]. Selain itu selain efisiensi pada hasil jumlah komponen dan berat alat juga turut menjadi perhatian dimana topologi tersebut membutuhkan banyak lebih banyak komponen jika ingin menaikkan atau menurunkan tegangan dengan rasio yang tinggi.

Untuk menjawab tantangan tersebut dalam proposal ini mengajukan sebuah topologi baru DC-DC konverter untuk sistem photovoltaic dengan beberapa keuntungan berikut yaitu : Integrasi konverter yang mudah dimana dapat megurangi jumlah saklar dan kompenen yang tidak terlalu diperlukan, rasio peningkatan tegangan tinggi yang bisa dicapai oleh konverter, ripel arus keluaran yang rendah , dan terjaganya karakteristik konverter DC-DC.

\section{URAIAN PENELITIAN}

\section{A. Topologi Konverter Quadratic Boost Zeta}

Topologi Konverter DC-DC Rasio Tinggi berbasis Integrated quadratic boost zeta merupakan topologi gabungan dari konverter quadratic boost dan konverter zeta dengan ditambah dengan induktor kopel sebagai penaik tegangan. Topologi ini memeliki beberapa keuntungan diantaranya, komponen yang sedikit dan rasio peningkatan tegangan yang tinggi [4]. Berikut adalah gambar dari rangkaian konverter topologi Integrated quadratic boost zeta:

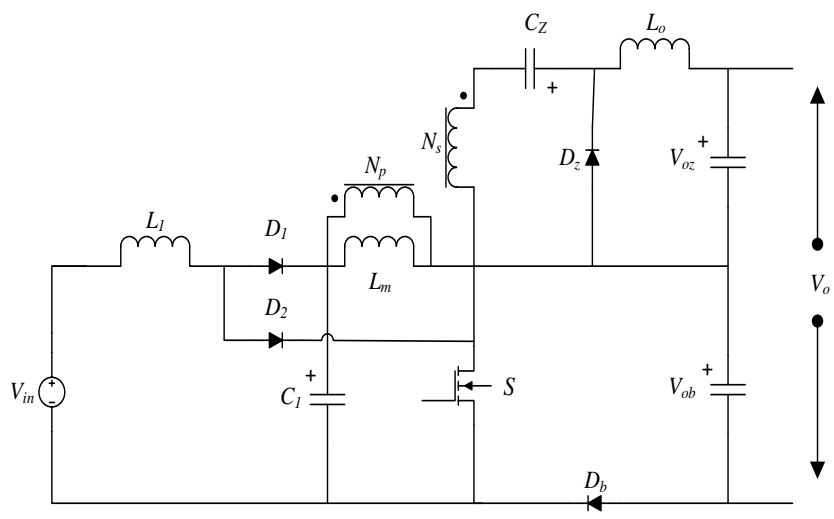

Gambar 1 Konverter Integrated Quadratic Boost Zeta 

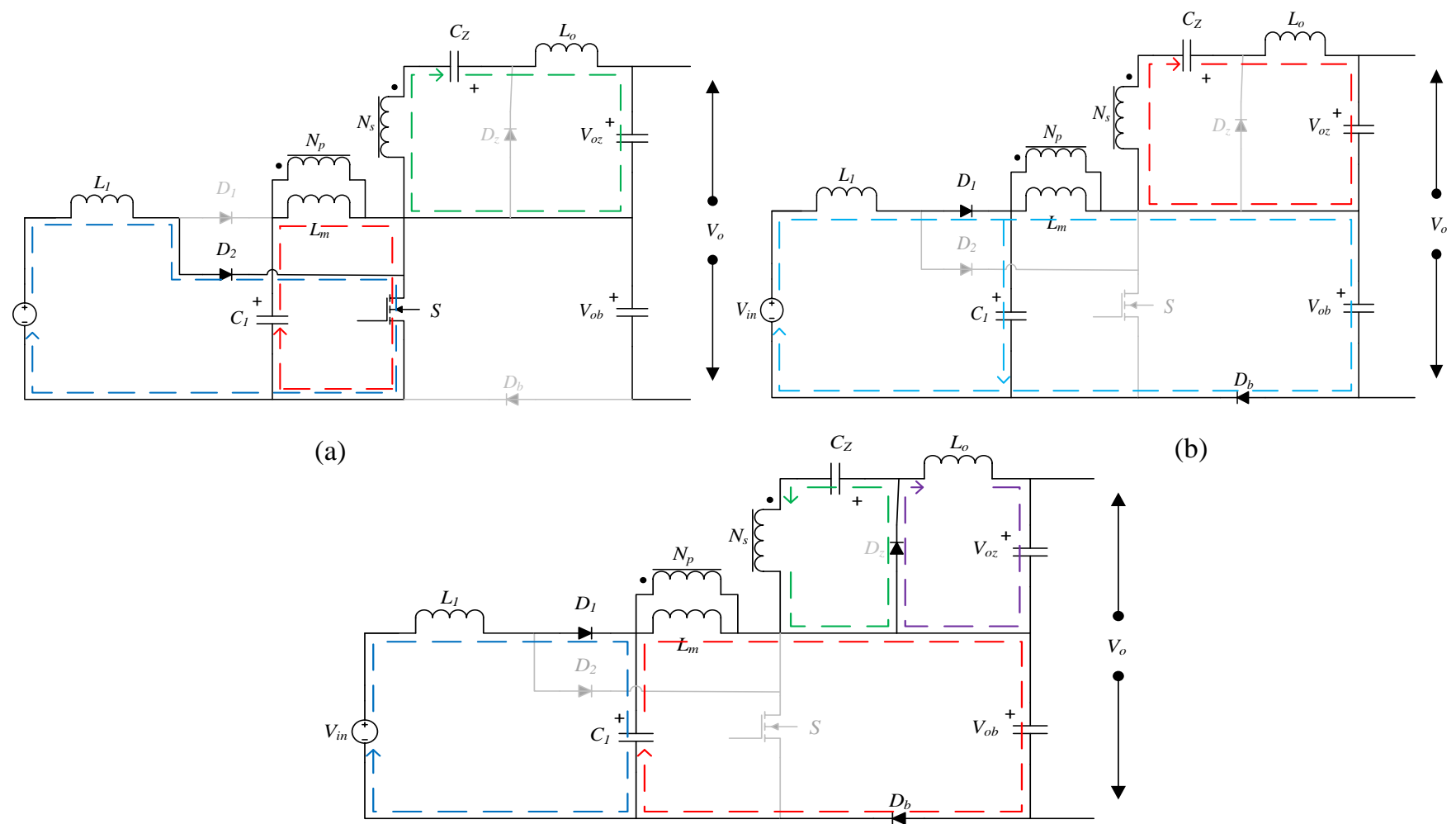

(b)

(c)

Gambar 2. Mode Operasi Konverter

Tegangan output dari konverter merupakan penjumlahan dari 2 konverter yang telah disebutkan dimana $\mathrm{V}_{\mathrm{oz}}$ merupakan output dari konvereter zeta sementara $\mathrm{V}_{\mathrm{ob}}$ merupakan output dari konverter quadratic boost. Untuk menjelaskan bagaimana prinsip kerja dari konverter diatas kita dapat menganalisa dari aliran arus pada setiap waktu.

\section{B. Mode Operasi Konverter}

Konvereter topologi ini memiliki 3 mode operasi yaitu $t_{0^{-}}$ $\mathrm{t}_{1}, \mathrm{t}_{1}-\mathrm{t}_{2}$ dan $\mathrm{t}_{2}-\mathrm{t}_{3}$ [3]. Pada saat mode satu $\left(\mathrm{t}_{0}-\mathrm{t}_{1}\right)$ ditunjukkan oleh gambar 2(a) atau ketika saklar tertutup Dioda $\mathrm{D}_{1}$ akan mengalami reverse bias akibat Tegangan kapasitor $\mathrm{V}_{\mathrm{Cl}}$. Dioda $D_{b}$ dan dioda $D_{Z}$ juga mengalami reverse bias masing-masing akibat dari $\mathrm{V}_{\mathrm{oz}}$ dan $\mathrm{V}_{\mathrm{ob}}$. Dioda $\mathrm{D}_{2}$ mengalami konduksi. Induktor $\mathrm{L}_{1}$, induktor $\mathrm{L}_{2}$ dan induktor $\mathrm{L}_{\mathrm{o}}$ mengalami proses pengisian energy masing-masing oleh tegangan input $\mathrm{V}_{\mathrm{in}}$, tegangan kapasitor $1 \mathrm{~V}_{\mathrm{C} 1}$ dan teganga induktor kopel sekunder, oleh karena itu arus induktor $\mathrm{I}_{\mathrm{L} 1}$ $\mathrm{I}_{\mathrm{Lm}}$ dan $\mathrm{I}_{\mathrm{Lo}}$ akan mengalami kenaikan. Kapasitor satu $\mathrm{C}_{1}$ dan kapasitor zeta $\mathrm{C}_{\mathrm{z}}$ mengalami pelepasan energi dan kapasitor output $\mathrm{C}_{\mathrm{oz}}$ dan $\mathrm{C}_{\mathrm{ob}}$ mengalami fase pengisian energi.

Pada mode operasi dua ( $\mathrm{t} 1-\mathrm{t} 2)$ seperti ditunjukkan pada gambar 2 (b) ketika saklar $S$ baru saja terbuka. Dioda $D_{2}$ dan dioda $\mathrm{Dz}$ akan mengalami reverse bias akibat tegangan output quadratic boost $\mathrm{V}_{\mathrm{ob}}$ dan tegangan kapasitor zeta $\mathrm{V}_{\mathrm{Cz}}$. Sementara itu dioda $\mathrm{D}_{1}$ dan dioda $\mathrm{D}_{\mathrm{b}}$ akan mengalami mode konduksi. Induktor $\mathrm{L}_{1}$, induktor $\mathrm{L}_{2}$ dan induktor $\mathrm{L}_{\mathrm{o}}$ mengalami proses pelepasan energi akibatnya arus pada induktor tersebut akan turun. Kapasitor $C_{1}$ dan kapasitor $C_{z}$ mengalami pengisian energi pada mode ini.

Pada mode operasi tiga $\left(\mathrm{t}_{2}-\mathrm{t}_{3}\right)$ seperti ditunjukkan pada gambar 2(c) atau ketika saklar S telah terbuka, hanya Dioda $\mathrm{D}_{2}$ yang akan mengalami reverse bias akibat tegangan $\mathrm{V}_{\mathrm{ob}}$ sedangkan dioda $\mathrm{D}_{\mathrm{z}}$ akan kembali mengalami mode konduksi karena tegangan $\mathrm{V}_{\mathrm{ob}}$ dan tegangan $\mathrm{V}_{\mathrm{Lm}}$. Dioda $\mathrm{D}_{1}$ dan dioda $D_{b}$ juga akan mengalami mode konduksi masingmasing karena tegangan kapasitor $\mathrm{V}_{\mathrm{C} 1}$ dan tegangan $\mathrm{V}_{\mathrm{ob}}$. Induktor $\mathrm{L}_{1}$, induktor $\mathrm{L}_{2}$ dan induktor $\mathrm{L}_{\mathrm{o}}$ mengalami proses pelepasan energi akibatnya arus pada induktor tersebut akan mengalami penurunan. Sementara kapasitor $\mathrm{C}_{1}$ dan kapasitor $\mathrm{C}_{\mathrm{z}}$ mengalami pengisian energi pada mode ini .

\section{Analisis Topologi}

Dengan menganlisisis aliran arus pada setiap mode operasi bisa didapatkan persamaan rasio konversi dan nilai parameter dari konverter. Semua perhitungan dilakukan dalam kondisi ideal sehingga dianggap tidak ada pengurangan tegangan pada komponen dan membuat daya input sama dengan nilai daya output konverter. Dalam menentukan persamaan rasio konversi tegangan konverter, hanya mode operasi 1 dan 3 yang digunakan. Hal ini karena mode operasi 2 berlangsung sangat singkat. Dari penurunan rumus pada saat mode operasi 1 didapatkan :

$$
\begin{gathered}
V_{L 1}(\text { on })=V_{\text {in }} \\
V_{L m}(\text { on })=V_{C 1} \\
V_{L O}(\text { on })=\mathrm{N} V_{C 1}+V_{C 2}-V_{O Z}
\end{gathered}
$$

Sementara itu dari mode operasi 3 pada saat saklar off didapatkan :

$$
\begin{aligned}
& V_{L 1}(\text { off })=V_{i n}-V_{C 1} \\
& V_{L m}(\text { off })=V C_{1}-V_{o b} \\
& V L_{O}(\text { off })=-V_{o z}
\end{aligned}
$$

Dengan menggunakan prinsip Induktor Voltage Second Balance pada saat kondisi saklar on dan off pada setiap induktor didapatkan persamaan berikut :

$$
\int_{0}^{D T} V_{L 1}(\text { on }) d t+\int_{D T}^{T} V_{L 1}(\text { off }) d t=0
$$




$$
\begin{gathered}
\frac{V_{C 1}}{V_{i n}}=\frac{1}{1-D} \\
\int_{0}^{D T} V_{L m}(o n) d t+\int_{D T}^{T} V_{L m}(o f f) d t=0 \\
\frac{V_{o b}}{V_{C 1}}=\frac{1}{1-D} \\
\frac{V_{o b}}{V_{i n}}=\frac{1}{(1-D)^{2}} \\
\int_{0}^{D T} V_{L O}(\text { on }) d t+\int_{D T}^{T} V_{L O}(o f f) d t=0 \\
\frac{V_{O Z}}{V_{C 1}}=\frac{N D}{1-D}
\end{gathered}
$$

Dengan mesubtitusi persamaan (8) ke persamaan (13) maka akan diperoleh penguatan akhir dari sisi konverter zeta.

$$
\frac{V_{O Z}}{V_{\text {in }}}=\frac{N D}{(1-D)^{2}}
$$

Telah diketahui penurunan persamaan dari masingmasing konverter maka untuk mendapatkan tegangan keluaran dari integrasi konverter kita hanya perlu menjumlahkan kedua persamaan tersebut.

$$
V_{o}=V_{o b}+V_{O Z}
$$

Sehingga didapatkan persamaan akhir penguatan konverter adalah :

$$
M=\frac{V_{o}}{V_{\text {in }}}=\frac{1+N D}{(1-D)^{2}}
$$

Untuk Menghitung nilai dari induktor maka perlu diketahui besar arus yang mengalir pada setiap induktor tersebut. Besar arus pda induktor $\mathrm{L}_{1}, \mathrm{~L}_{\mathrm{m}}$ dan $\mathrm{L}_{\mathrm{o}}$ adalah sebagai berikut:

$$
\begin{gathered}
I_{L 1}=\frac{(1+N D)^{2}}{R(1-D)^{4}} V_{i n} \\
I_{L m}=\frac{(1+N D)^{2}}{R(1-D)^{3}} V_{C 1} \\
I_{L o}=\frac{V_{O}}{R}
\end{gathered}
$$

Dengan menentukan spesifikasi nilai dari ripple arus maka nilai induktor dapat dicari dengan persamaan berikut :

$$
\begin{gathered}
L_{1}=\frac{V_{\text {in }} D}{f \Delta I_{L 1}} \\
L_{m}=\frac{V_{i n} D}{(1-D) f \Delta I_{L m}} \\
L_{o}=\frac{N V_{C 1} D}{f \Delta I_{O}}
\end{gathered}
$$

Dengan menentukan nilai dari ripple tegangan maka nilai

\begin{tabular}{|c|c|}
\hline Parameter & Nilai \\
\hline Po & 50 Watt \\
\hline Vo & 330 Volt \\
\hline $\operatorname{Vin}(\min )$ & 14 Volt \\
\hline $\operatorname{Vin}(\max )$ & 18 Volt \\
\hline $\mathrm{N}$ & 2 \\
\hline Frekuensi Pensaklaran & $50 \mathrm{kHz}$ \\
\hline Ripel Tegangan $(\Delta \mathrm{V})$ & $1 \%$ \\
\hline Ripel Arus $(\Delta \mathrm{I})$ & $30 \%$ \\
\hline
\end{tabular}
kapasitor dapat diketahui dari persamaan berikut :

$$
\begin{gathered}
C_{1}=\frac{(1+N D)^{2}}{R(1-D)^{2}} \frac{D V_{C 1}}{f \Delta V_{C 1}} \\
C_{2}=\frac{V_{o} D}{f R \Delta V_{o Z}} \\
C_{o z}=\frac{(1-D) V_{o Z}}{8 f^{2} L_{o} \Delta V_{o z}} \\
C_{o b}=\frac{V_{o} D}{f R V_{o b}}
\end{gathered}
$$

\section{DESAIN, SIMULASI DAN IMPLEMENTASI}

A. Desain

Sebelum merancang nilai kapasitas komponen seperti induktor dan kapasitor, maka terlebih dahulu ditentukan parameter-parameter elektris lain yang digunakan pada konverter ini terlebih dahulu

Tabel 1.

Spesifikasi awal desain konverter

Dengan memasukkan tegangan input dan tegangan maka nilai penguatan tegangan pada saat tegangan input $V_{\text {in }} 14$ volt dan 18 Volt dapat diketahui:

$$
\begin{aligned}
& M 1=\frac{330}{14}=23.6 \\
& M 2=\frac{330}{18}=18,3
\end{aligned}
$$

nilai duty cycle pada saat tegangan input 14 dan 1:

$$
\begin{aligned}
& \mathrm{D}_{1}=68.32 \% \\
& \mathrm{D}_{2}=64.64 \%
\end{aligned}
$$

Besar beban ketika daya input sebesar 50W

$$
R=\frac{(330)^{2}}{50}=2178 \Omega
$$

Konverter didesain untuk beroperasi pada mode CCM (Continuous Conduction Mode) sehingga membuat arus induktor tidak boleh menyentuh titik 0.. Nilai ripple arus induktor didesain $30 \%$ dari nilai I rata-rata yang mengalir pada induktor. Dengan mengetahui nilai arus rata-rata yang mengalir pada induktor maka nilai induktor untuk implementasi dapat dihitung:

$$
\begin{gathered}
L_{1}=\frac{18 \times 0.6464}{5000 \times 0.3 \times 2.778}=279,072 \mu \mathrm{H} \\
L_{m}=\frac{18 \times 0.6464}{(1-6464) \times 50000 \times 0.3 \times 0.983}=2,237 \mathrm{mH} \\
L_{o}=\frac{2 \times 0.6464}{50000 \times(1-0.6464) \times 0.3 \times 0.1515}=28,946 \mathrm{mH}
\end{gathered}
$$

Dengan diketahuinya nilai tegangan dari masing-masing kapasitor maka penentuan nilai kapasitor selanjutnya bisa dilakukan dengan berdasarkan pada persamaan (2.94), (2.96), (2.100) dan (2.105).

$$
\begin{gathered}
C_{1}=\frac{(1+2 \times 0.6464)^{2} \times 0.6464}{2178 \times(1-0.6464)^{2} \times 5000 \times 0.01}=24,96 \mu \mathrm{F} \\
C_{2}=\frac{330 \times 0.6464}{2178 \times 50000 \times 0.01 \times 186.114}=1,055 \mu \mathrm{F} \\
C_{O Z}=\frac{(1-0.6464)}{8 \times(50000)^{2} \times 0.002895 \times 0.01}=61,23 \mathrm{nF} \\
C_{o b}=\frac{330 \times 0,6464}{50000 \times 2178 \times 143.637}=1,36 \mu \mathrm{F}
\end{gathered}
$$

nilai ripple tegangan $\Delta \mathrm{V}$ didesain $1 \%$ dari tegangan rata-rata yang mengalir pada kapasitor.Penentuan nilai kapasitor dilakukan ketika tegangan 18 Volt untuk menjaga agar nilai kapasitor selalu diatas nilai perhitungan dan nilai dari ripple tegangan tidak berada dibawah deain yang ditentukan. 


\section{B. Simulasi}

Simulasi dilakukan dengan menggunakan software dengan memasukkan nilai dari parameter-parameter yang telah dihitung sebelumnya. Semua parameter yang ada pada rangkaian merupakan komponen ideal dengan sumber DC konstan sebesar $18 \mathrm{~V}$ dan beban resistor $2178 \Omega$. Sinyal input pada gate MOSFET dimodelkan dengan gelombang PWM (Pulse Width Modulation) dengan frekuensi $50 \mathrm{kHz}$ dan duty cycle $64,64 \%$ sesuai perhitungan. Induktor kopel dimodelkan dengan rangkaian cantilever model sesuai dengan gambar 1, namun nilai dari induktor bocor $\mathrm{L}_{\mathrm{k}}$ dianggap tidak ada atau sama dengan 0 sehingga sisi anoda dioda $\mathrm{D}_{1}$ langsung terhubung dengan induktor magnetisasi

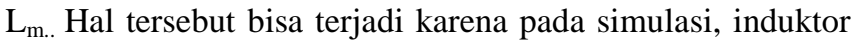
kopel merupakan induktor kopel ideal.

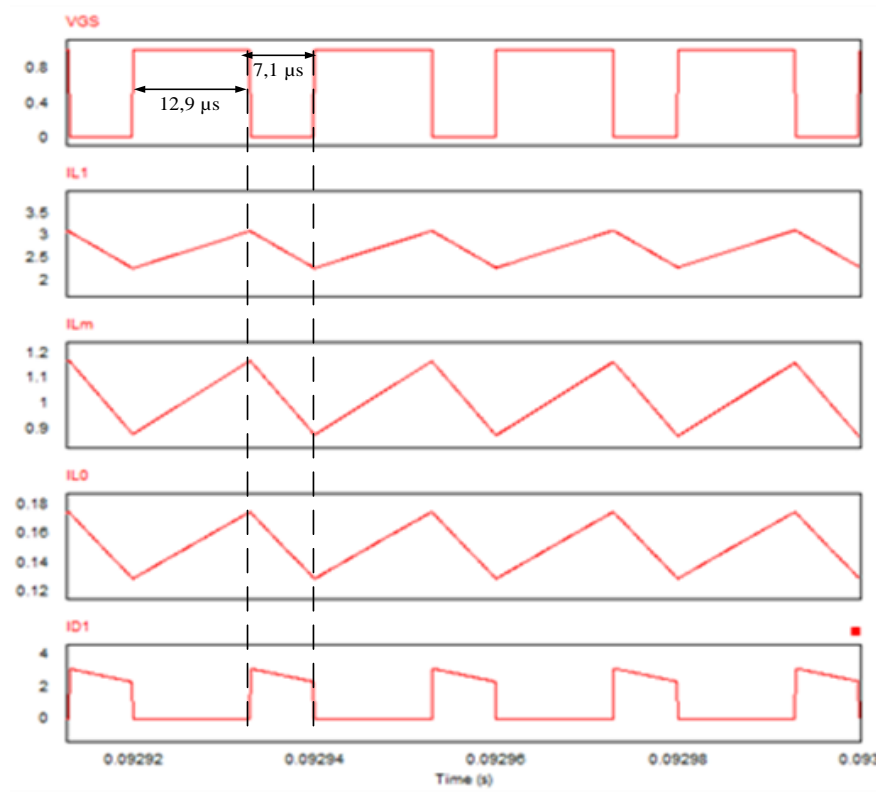

Gambar 3 Bentuk gelombang arus pada induktor
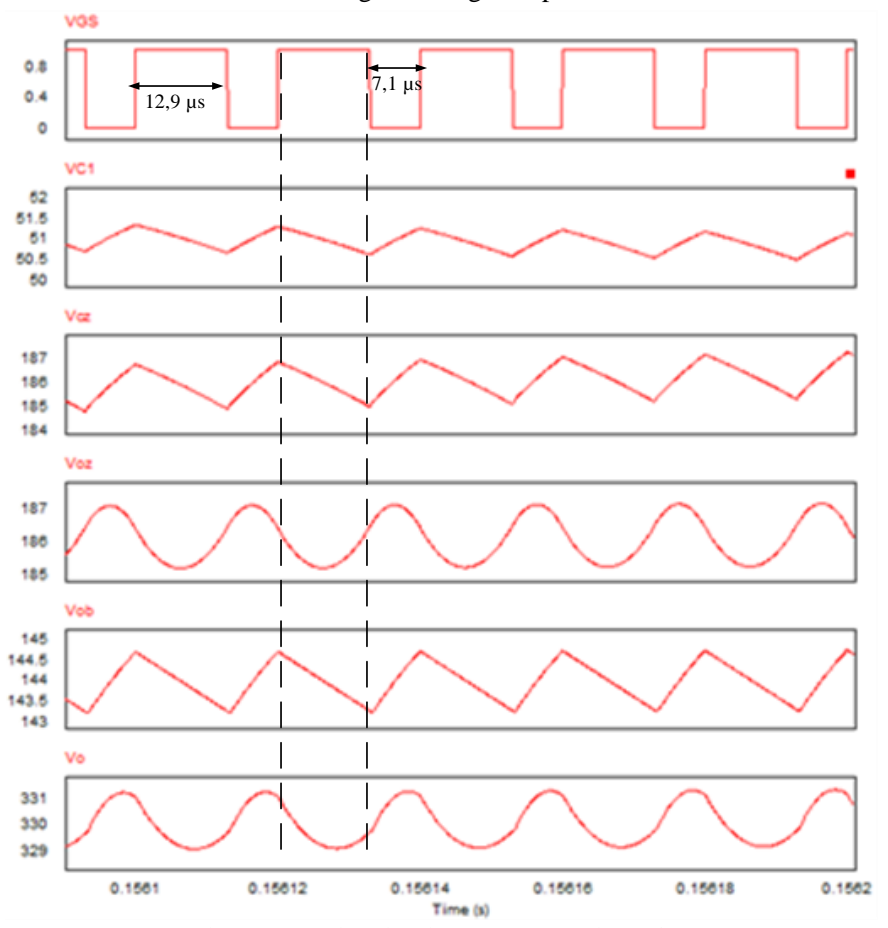

Gambar 4 Bentuk gelombang tegangan kapasitor
Gambar 3 menunjukkan bentuk gelombag arus dari setiap induktor. Pada gambar tersebut juga ditunjukkan bentuk gelombang dari dioda $\mathrm{D}_{1}$ karena ketika terdapat induktor bocor pada rangkaian bentuk gelombang dari induktor bocor akan sama dengan arus pada diodA. Dari gambar tersebut menunjukkan bahwa induktor input $\mathrm{L}_{1}$, induktor magnetisasi $\mathrm{L}_{\mathrm{m}}$, dan induktor output $\mathrm{L}_{\mathrm{o}}$ akan mengalami fase charging ketika $\mathrm{V}_{\mathrm{GS}}$ dalam kondisi on. Pada gambar 4 menuunjukkan bahwa pada saat $\mathrm{V}_{\mathrm{GS}}$ off kapasitor $\mathrm{C}_{1}, \mathrm{C}_{\mathrm{z}}$, $\mathrm{C}_{\mathrm{ob}}$ berada dalam fase charging hal ini sudah sesuai dengan analisis yang telah dijelaskan.

\section{Implementasi}

PWM menggunakan microcontroller Arduino Uno dengan output $5 \mathrm{~V}$ peak to peak dan frekuensi $50 \mathrm{kHz}$. Sinyal PWM dimasukkan ke LCD 16X2 untuk menampilkan duty cycle dari PWM, dimana duty cycle bisa diatur dengan resistor variable multi turn. Induktor kopel dirancang memiliki nilai penguatan sebesar 2 dengan belitan primer sebesar 24, belitan sekunder sebanyak 48 namun karena terdapat induktor bocor pada induktor kopel $\mathrm{L}_{\mathrm{k}}=8,18 \mu \mathrm{H}$, sehingga nilai penguatan tegangan tidak sama dengan nilai perbandingan belitan nilai penguatan menjadi sebesar 1,8 [5].

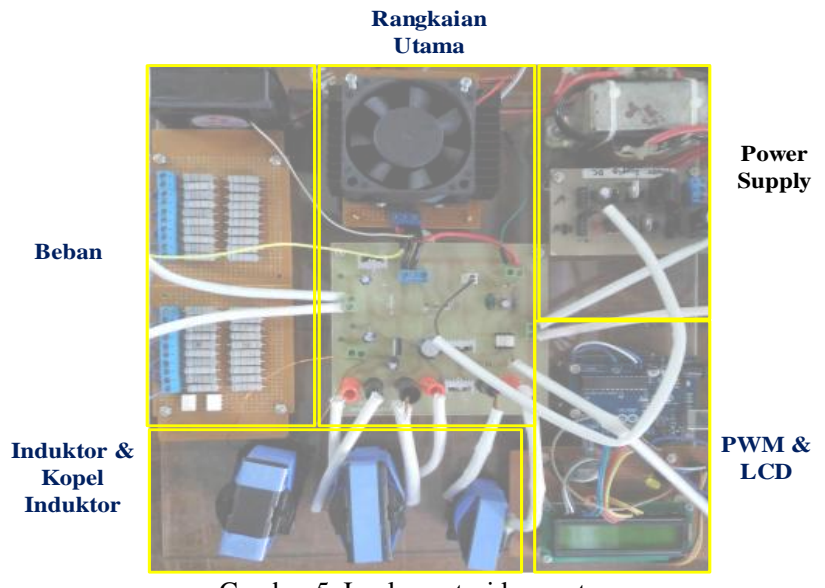

Gambar 5. Implementasi konverter

Tabel 2

Spesifikasi Komponen Rangkaian Konverter

\begin{tabular}{ccc}
\hline \hline Komponen & Desain Awal /Simulasi & $\begin{array}{c}\text { Nilai } \\
\text { implementasi }\end{array}$ \\
\hline Induktor L1 & $279,07 \mu \mathrm{H}$ & $294,5 \mu \mathrm{H}$ \\
Induktor Kopel & & \\
$\mathrm{L}_{11}$ & $2,24 \mathrm{Mh}$ & $2,844 \mathrm{Mh}$ \\
$\mathrm{L}_{\mathrm{m}}$ & $2,24 \mathrm{Mh}$ & $2,836 \mathrm{Mh}$ \\
$\mathrm{L}_{22}$ & Tidak bisa dihitung & $9,298 \mathrm{Mh}$ \\
$\mathrm{L}_{\mathrm{k}} / \mathrm{L}_{12}$ & - & $8,18 \mu \mathrm{H}$ \\
$\mathrm{L}_{\mathrm{o}}$ & $28,9 \mathrm{Mh}$ & $32 \mathrm{Mh}$ \\
$\mathrm{N}$ (Penguatan & 2 & 1,82 \\
tegangan) & $24,96 \mu \mathrm{F} / 51 \mathrm{~V}$ & $33 \mu \mathrm{F} / 160 \mathrm{~V}$ \\
Kapasitor $\mathrm{C}_{1}$ & $1.055 \mu \mathrm{F} / 186 \mathrm{~V}$ & $2,2 \mu \mathrm{F} / 250 \mathrm{~V}$ \\
Kapasitor $\mathrm{C}_{2}$ & $1.36 \mu \mathrm{F} / 143,6 \mathrm{~V}$ & $2,2 \mu \mathrm{F} / 250 \mathrm{~V}$ \\
Kapasitor $\mathrm{C}_{\mathrm{ob}}$ & $61,2 \mathrm{Nf} / 186 \mathrm{~V}$ & $1 \mu \mathrm{F} / 250 \mathrm{~V}$ \\
Kapasitor $\mathrm{C}_{\mathrm{oz}}$ & $\mathrm{Ideal}$ & $\mathrm{MUR} 1560$ \\
Dioda & $\mathrm{Ideal}$ & $\mathrm{IRFP} 460$ \\
MOSFET & - & $\mathrm{TLP} 250$ \\
Driver MOSFET & & \\
\hline \hline
\end{tabular}




\section{PENGUJIAN}

\section{A. Pengujian Gelombang Pensaklaran}

Pengujian dilakukan untuk mengetahu apakah bentuk gelombang dari setiap kaki MOSFET dan diode sudah sesuai dengan perancangan dan simulasi yang dilakukan. Gambar 6 menunjukkan bahwa konverter mampu bekerja pada mencapai tegang output 330 Volt pada saat Duty cycle $=65,92 \%$ dan Vinput $=18$ Volt. Dari gambar tersebut juga diketahui bahwa VGS, VDS sudah bekerja sebagaimana mestinya dimana bentuk gelombang dari VGS dan VDS berkebalikan.

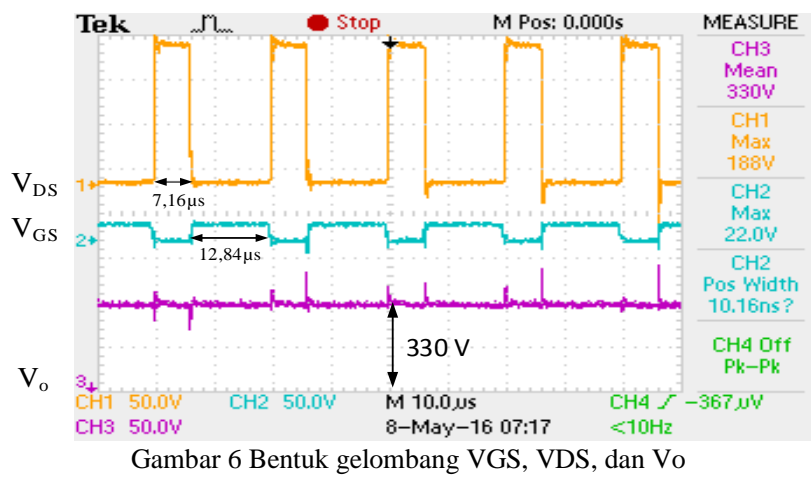

\section{B. Pengujian arus induktor dan tegangan kapasitor}

Dari gambar 7 dapat dianalisis bahwa pada saat saklar utama konduksi,induktor mengalami charging energi sehingga arus induktor $I_{L I}$ mengalami peningkatan. Nilai arus induktor $I_{L I}$ selalu berada diatas nol, menunjukkan bahwa konverter beroperasi secara CCM. Besar ripple arus pada induktor $L_{1}$ adalah $0.8 \mathrm{~A}$. Jika di bandingkan dengan nilai arus rata-rata maka nilai ripple adalah 24 persen nilai ini berada dibawah desain yaitu $30 \%$ hal tersebut karena desain nilai induktor diperbesar sehingga ripple arus mengecil.

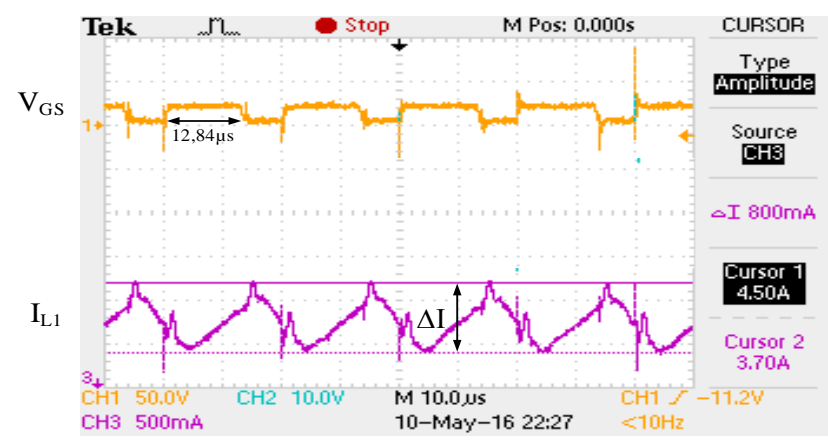

Gambar 7. Bentuk gelombang arus induktor $\mathrm{I}_{\mathrm{L} 1}$

Gambar 8 menunjukan bentuk gelombang dari arus induktor $L_{k}$ (leakage) yang tidak lain merupakan bentuk arus gelombang dari diode 1 . Diketahui arus $L_{k}$ (leakage) / arus dioda 1 berkebalikan dengan bentuk gelombang gate-sourse $\mathrm{V}_{\mathrm{GS}}$ hal ini telah sesuai dengan simulasi .

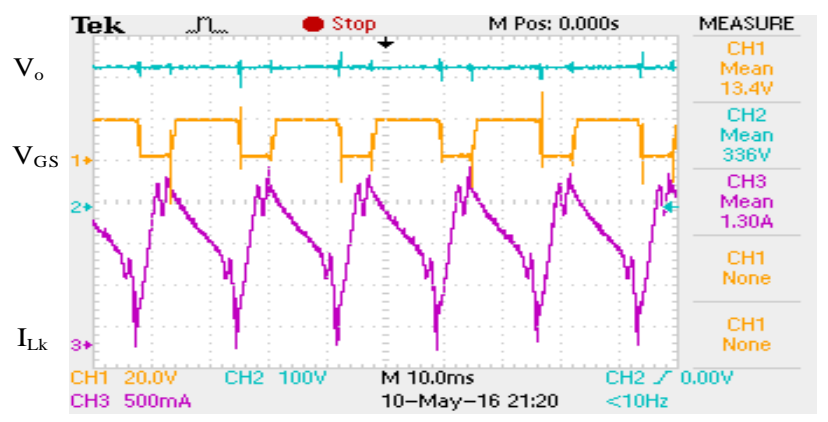

Gambar 8. gelombang arus induktor bocor $\mathrm{I}_{\mathrm{Lk}}$

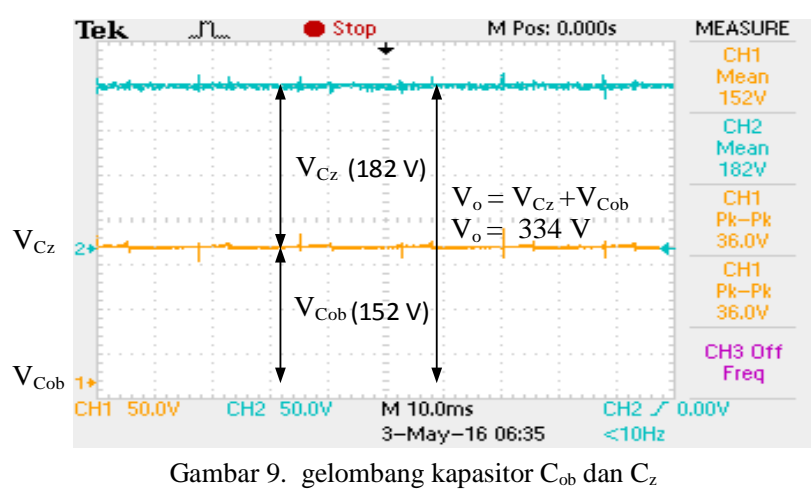

Gambar 9 menunjukkan bahwa tegangan output konverter yang bernilai 334 volt merpakan penjumlahan dari tegangan kapasitor output pada sisi quadratic boost $\mathrm{V}_{\mathrm{Cob}}$ dan tegangan kapasitor output pada sisi zeta $\mathrm{V}_{\mathrm{Cz}}$.

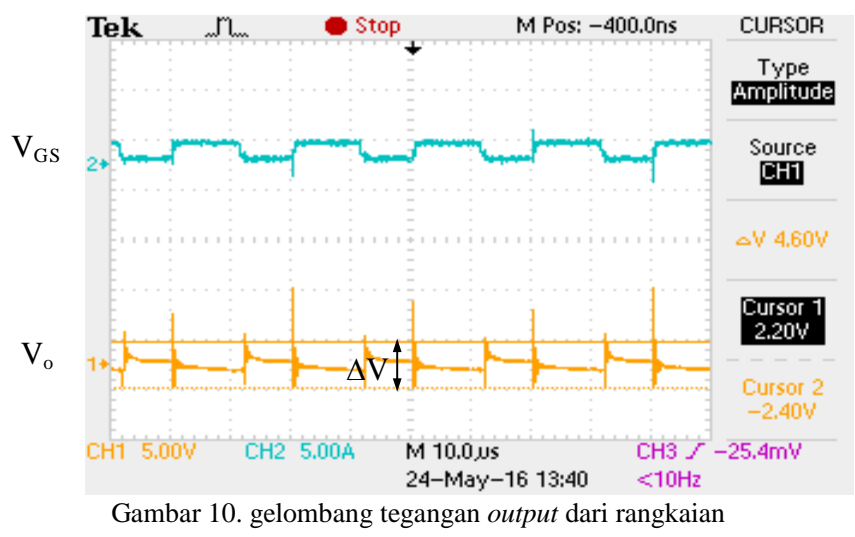

Gambar 10 menunjukkan bahwa nilai ripple tegangan keluaran dari konverter bernlai $4,6 \mathrm{~V}$, artinya $1.3 \%$ dari tegangan keluaran konverter. Hasil ini sedikit lebih besar dari ripple tegangan yang direncanakan yaitu 1\%. Selisih nilai bisa terjadi karena ketidak idealan kompenen yang tersedia dipasaran. Pada kapasitor implementasi terdapat efek parasit komponen dapat dijelaskan menggunakan konsep equivalent series resistance (ESR).

\section{Pengujian Rasio Konversi}

Pada pengujian rasio konversi konverter DC-DC rasio tinggi ini diberi tegangan input tetap 18 Volt sementara Duty cycle-nya dinaikkan dengan interval tetap sehingga tegangan output juga akan naik 


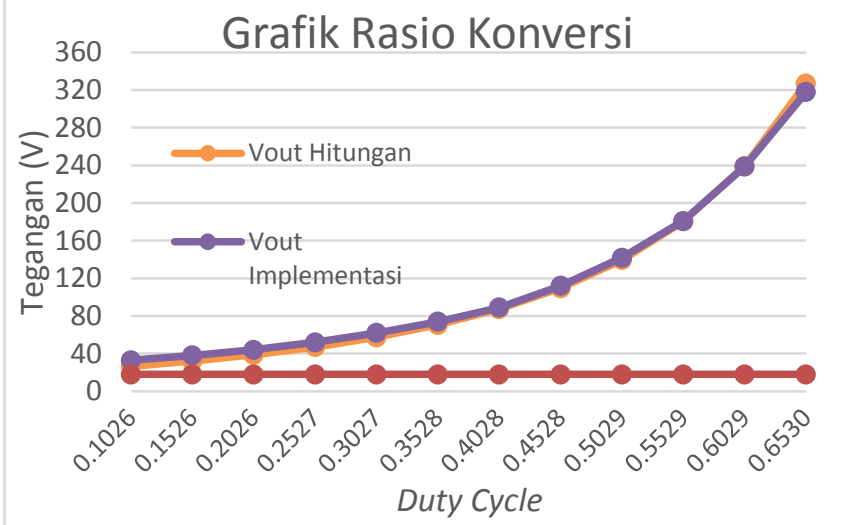

Gambar 11 Grafik Rasio Konversi dengan DC (0\%-65\%)

Dari gambar 4.9 diatas menunjukkan bahwa perbandingan kenaikan tegangan ouput antara hitungan dan implementasi relatif sama namun ketika duty cycle melebihi $60 \%$ mulai terjadi drop pada tegangan output implementasi. Hal tersebut bisa terjadi karena adanya parasit komponen pada alat dan keterbatasan dari inti induktor untuk menahan tegangan yang tinggi..

\section{Pengujian Efisiensi}

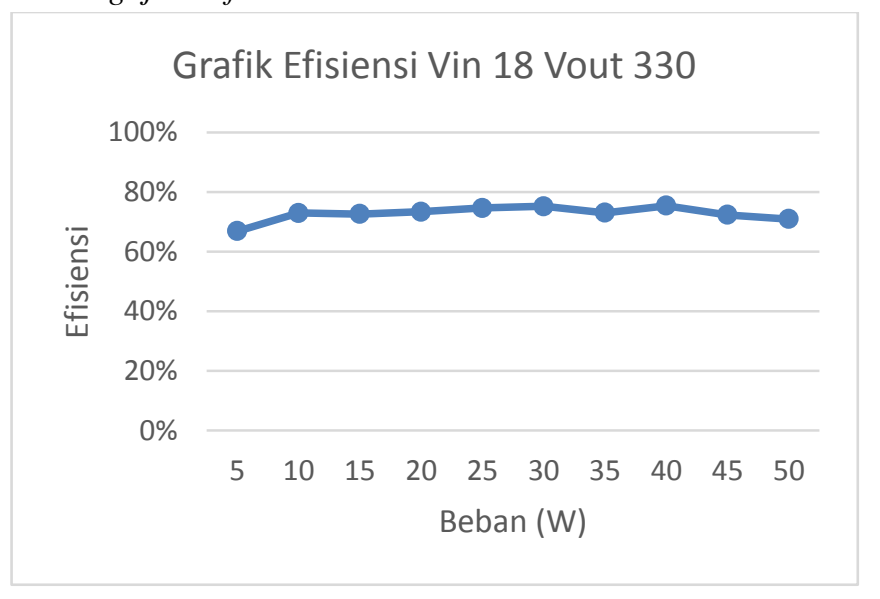

Gambar 12 Grafik Efisiensi Konverter

Beban $100 \%$ merupakan beban perancangan yaitu 50 Watt dan beban $10 \%$ berarti $10 \%$ dari 50 Watt sama dengan 5 Watt Dari hasil uji efisisensi pada tegangan input $18 \mathrm{~V}$ dan tegangan output 330 Volt dengan beban diturunkan dari $10 \%$ ke $100 \%$ menunjukkan bahwa efisiensi konverter relatif stabil diantara $70 \%-75 \%$ seperti ditunjukkan pada gambar 12 hal tersebut terjadi akibat dari ESR(Equivalent Series resistor) yang ada pada tiap komponen dan adanya induktor bocor. Pada saat beban $10 \%$ efisiensi konverter menurun karena arus yang mengalir pada konverter terlalu kecil sehingga nilai drop tegangan akan menjadi besar bila dibandingkan nilai tersebut.

\section{E. Pengujian Menggunakan Photovoltaic}

Beban yang digunakan adalah beban $50 \%$ dari perancangan hal tersebut karena pada saat pengujian jika beban dibebani $100 \%$ tegangan output maksimum terukur sangat kecil. Ketika konverter dibebani 50\% tegangan output konverter mampu mencapai $280 \mathrm{~V}$ namun untuk menjaga agar tegangan output bisa mudah tercapai pengujian dilakukan dengan tegangan output konstan sebesar 250 V. Gambar 13 menunjukkan nilai tegang input dan tegangan output dari konverter dimana tegangan output mampu dijaga tetap hanya dari pukul 09.00-15.00 setalah melebihi waktu tersebut terjadi drop pada tegangan output karena berkurangnya iradian.

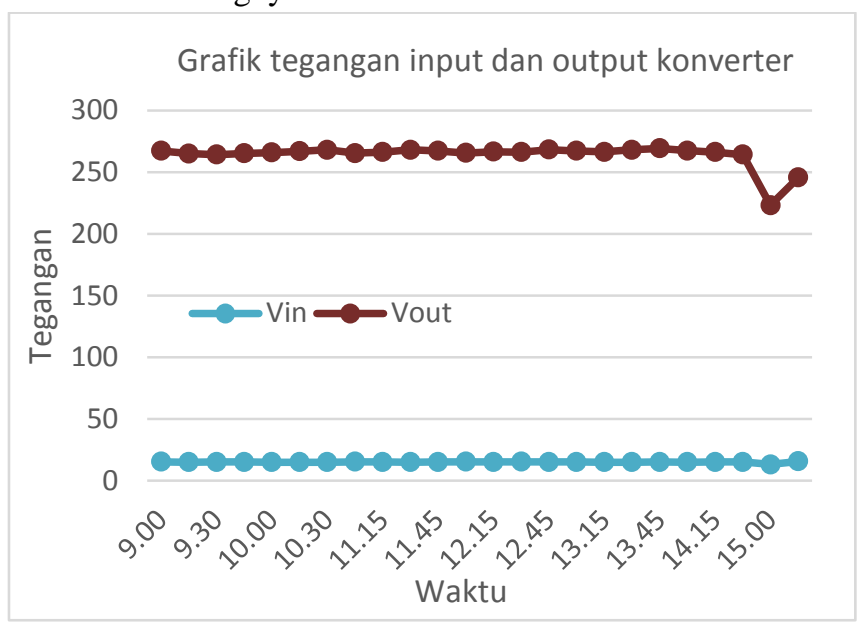

Gambar 13. Grafik percobaan dengan Photovoltaic

\section{KESIMPULAN}

Berdasarkan analisis data , hasil simulasi dan implementasi pada konverter DC-DC rasio tinggi berbasis integrated quadratic boost zeta untuk aplikasi photovoltaic dapat disimpulkan beberapa hal sebagai berikut :

1. konverter DC-DC rasio tinggi berbasis integrated quadratic boost zeta dapat mencapai rasio tinggi sesuai desain yaitu 18,33 kali

2. Terjadi drop tegangan yang tinggi ketika konverter dioperasikan pada duty cycle $65 \%$ yaitu sebesar 9 volt

3. Konverter memiliki efisiensi antara $70 \%-75 \%$, hal ini karena adanya keterbatasan inti yang dipakai untuk merangkai induktor dengan nilai yang besar.

\section{DAFTAR PUSTAKA}

[1] Y. Zhao W. Li Y. Deng X. He., High step-up boost converter with passive lossless clamp circuit for nonisolated high step-up applications, ET Power Electron., Vol. 4, Iss. 8, pp. 851-859, 2011

[2] Hart, Daniel W. "Power Electronics", MCCGrawHill, New York, 2011

[3] Andrade, A. M. S. S.; Dreher, J. R.; Martins, M. L. S.;High Step-up Integrated DC-DC Converters: Methodology of Synthesis and Analysis,Power Electronics Conference (COBEP), 2013

[4] António M. S. S. Andrade, Rafael C. Beltrame, Luciano Schuch, Mário L dan S. Martins, "AIntegrated Quadratic-Boost-Zeta Converter for High Voltage Gain Applications" Federal University of Santa Maria, UFSM.Av. Roraima, 1000, Santa Maria, RS, Brazil, IEEE , 2014

[5] Hesterman Bryce, "Analysis and Modeling of Magnetic Coupling" Denver Chapter, IEEE Power Electronics Society, 2007 